
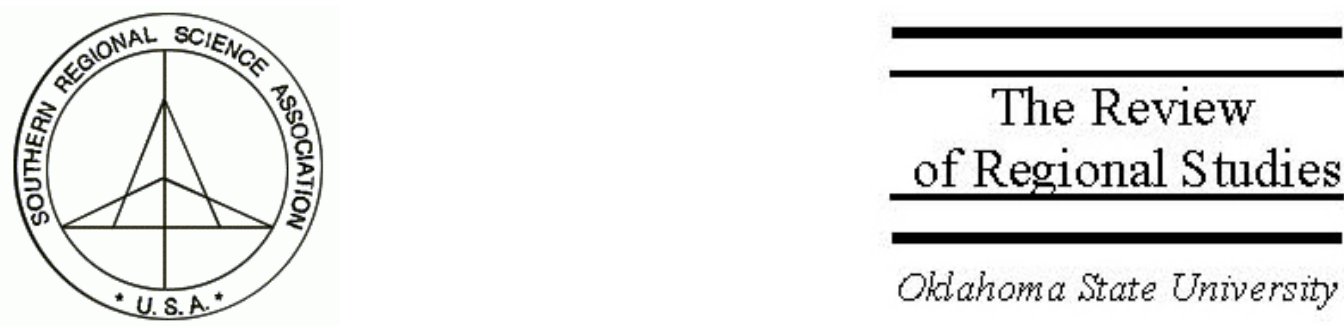

Oklahoma State University

\title{
An Application of the Regression Analogue of the Demographically Enhanced Shift-Share Model
}

\author{
James Brox \\ Department of Economics, University of Waterloo, 200 University Avenue, Waterloo \\ Ontario, Canada, N2L 3G1, e-mail: jbrox@watarts.uwaterloo.ca \\ Emanuel Carvalho \\ Department of Economics, University of Waterloo, 200 University Avenue, Waterloo \\ Ontario, Canada, N2L 3G1
}

\begin{abstract}
The objective of this research is to investigate employment patterns by age-sex specific cohorts through the application of a modified version of the shift-share model and in the process incorporating the Patterson (1991) regression analogue. Are older workers becoming unemployed or encouraged to take early retirement? Has the shift to less physically demanding employment across industries benefited females? The results of this study clearly indicate that adult workers have fared better than either younger or older workers in terms of relative employment growth, suggesting that the trend towards early retirement has not significantly reduced the employment problem facing younger cohorts.
\end{abstract}

Keywords: Demographically enhanced shift-share model; Full-analogue regression model

JEL classification: J08; R11 


\section{INTRODUCTION}

The objective of this paper is to investigate Canadian employment patterns by agesex specific cohorts through the application of a modified version of the shift-share model first suggested by Brox and Carvalho (2002) and then extended by Brox and Carvalho (2007) to account for labour-force changes. The process incorporates the Patterson (1991) regression analogue, which allows the effects to be tested for statistical significance. While a few past studies have investigated the employment prospects of different age-sex cohorts in relation to variables such as education levels, minimum wages, and retirement age (Bottoms 1981, Hostland 1985), this research offers an alternative view by utilizing the shift-share model to explore age-cohort employment patterns on a regional scale. Adapted to take into account different age groups, the shift-share model is employed to establish employment prospects by age-sex cohorts according to regional industrial concentration. The procedure involves focussing on annual employment changes extending over the time period 1976 to 1995 at the one-, two-, and three-digit SIC levels of industrial aggregation by region and age-sex cohort. In the process of separating employment by industry and region for different age groups, the shift-share model provides the basis for determining which of the various age-sex cohorts have fared better.

Some studies have begun to look closely at labour-market adjustments in response to structural shifts that may result in major changes to regional relationships, for example Dussel-Peters (1995) and Ehrenberg (1994) in relation to changes in the Mexican and American economies, respectively, following the formation of the North American Free Trade Agreement (NAFTA) and Blien and Wolf (2002) for Germany following reunification. Further, it has been argued that labour markets should be examined at a disaggregated level, specifically considering age-sex and possibly racial cohorts (Gabriel and Macdonald 1996; Anderson and Dimon 1999).

The paper attempts to offer insight to changing labour-force patterns observed by age and gender and certainly by industry and region. For instance, there is indication that younger workers facing difficulty in acquiring suitable employment opportunities are more likely to remain in school and pursue a post-secondary education. It also appears to be the case that older workers possessing obsolete skills become unemployed or are encouraged to take early retirement. Furthermore, the observed shift to less physically demanding employment opportunities across industries has benefited female workers. The analysis further accounts for interregional migration patterns and, in particular, the observed outflow of young more educated people from the Atlantic region and inflow of older segments of the population to British Columbia.

The remainder of the paper is organized as follows. In Section 2, we describe the theoretical form of the standard shift-share model, proposing modifications to allow for the extension of the analysis for various age-sex cohorts and the regression analogue. We analyze the results in Section 3, while in the final section we summarize the findings and suggest some policy implications arising from the analysis. 


\section{MODEL AND DATA REQUIREMENTS}

The conventional shift-share model has been used to assess regional development as measured on the basis of such variables as income, employment, value added, or a variety of others by separating growth into three components: (1) the national-growth component, which points to growth that would have occurred in the event that all industries in the study region had displayed the same rate of growth as the reference economy average; (2) the industry-mix component, which measures the effect of the existing industrial structure on regional growth by capturing the growth that would have occurred if the growth displayed by the existing regional industries had matched that exhibited by the same industries in the reference economy; and (3) the competitive or differential-shift component, which attributes regional growth to the dynamism or attractiveness of the region and is measured residually. The application of the shift-share model and, in particular, the relevance of the competitive-shift component have received extensive attention in the literature.

Some studies have been critical of the more conventional form and variations of the shift-share model. Other studies have pointed to the relevance of shift-share analysis as a useful tool for assessing and, to some degree, predicting regional economic development growth.

Studies including Houston (1967), Brown (1969), and Richardson (1978) criticized the shift-share model on the basis of five principle areas, including a lack of theoretical foundation, concerns regarding aggregation, weighting bias, instability of the competitive effect, and interdependence between the industry-mix and competitive effects.

In response to the first area of criticism, Chalmers and Beckhelm (1976) attempted to establish a theoretical context for the shift-share model by focussing on location theory. Fothergill and Gudgin (1979) contended that while it could be argued on theoretical grounds that the foundations of shift-share are questionable, the model does provide the basis for enabling the testing of the hypothesis. For instance, Andrikopoulos, Brox, and Carvalho (1990) showed that forecasts based on shift-share analysis produced more accurate results compared to analysis using aggregate employment changes. In addition, Ireland and Moomaw (1981) and Andrikopoulos, Brox, and Carvalho (1987) employed shift-share analysis in predicting investment decisions at the regional level, while Rigby and Anderson (1993) modified the shift-share model to investigate variations in labour productivity in Canada.

While concerns related to aggregation have been identified as a particular weakness attributed to shift-share models, a number of empirical studies, including those performed by Ashby (1968), Fothergill and Gudgin (1979), and Esteban (2000), suggest that shiftshare models are no more sensitive to the level of disaggregation than other regional analytical techniques.

Richardson (1978) proposed that factors such as business cycles, demographic shifts, and other similar events could produce a weighting bias directly attributed to the selection of the base year. The weighting bias was found to be minimal, especially in the short 
run, by McDonough and Sihag (1991) and can be accounted for in longer-term analysis through the application of a "dynamic shift-share model." In their empirical study of 11 regions in Britain, Fothergill and Gudgin (1979) further showed the effects of weighting to be relatively insignificant.

According to Brown (1969), instability of the competitive effect essentially rendered the shift-share model ineffective, both for the purposes of forecasting and policy analysis. This claim, however, was discounted by several studies, including Danson, Lever, and Malcolm (1980) in their analysis of urban areas in Britain, and demonstrated to be a relatively insignificant concern in the forecasting studies performed in regions such as Oklahoma by Ireland and Moomaw (1981) and Ontario and Quebec by Andrikopoulos, Brox, and Carvalho (1990).

The interdependence of components or its absence has evolved into the bases for assessing the validity of shift-share analysis as noted, for example, by Arcelus (1984) and Houston (1967). As a response, various studies proposed variations of the shift-share model designed to reduce the correlations between the industry mix and the competitive effects. A number of these modified versions of the shift-share were examined by Loveridge and Selting (1998), including models by Esteban-Marquillas (1972), Bishop and Simpson (1972), and Arcelus (1984). Loveridge and Selting concluded that the Esteban models do not alleviate the very problem they were designed to solve as one form of interdependence simply replaces another, a conclusion that was further supported by Keil (1992). According to Loveridge and Selting, if the significance of interdependence is allowed to be dismissed, the Esteban-Marquillas and Arcelus models become considerably more complex. They failed to meet what Loveridge and Selting termed "the zero national deviation property," that is, the industry mix and competitive effects summing to zero. Loveridge and Selting concluded that based on the empirical results and the opportunity for application by practitioners, "the classic model and its close substitutes are overall winners" (1998, p. 55).

More recently, shift-share analysis has been used to study changes in trade patterns (Markusen, Noponen, and Driessen 1991; Coughlin and Pollard 2001; Chebbi and Gil 2002), on effects of globalization and integration both in Europe (Esteban 2000; Melachroinos 2002; O'Leary 2003) and in North America following the formation of NAFTA (Ehrenberg 1994; Dussel-Peters 1995; Brox and Carvalho 2002), and in diversion or convergence in developing or transitional economies (Timmer and Szirmai 2000; Zhao, Tong and Qiao 2004). The so-called competitive share has frequently been found to be dominant, and it has been argued that this is often the result of human capital differences across the regions being considered.

The application of the conventional shift-share analysis normally involves assessing the industrial performance of a region in relation to the reference economy (often the national economy is used as the reference economy) by considering employment, which is the most readily available data, over all age groups according to the following specification: 


$$
\begin{aligned}
& N^{r}=E_{i}^{r} g^{n} \\
& I^{r}=E_{i}^{r}\left\{\left(g_{i}^{n}-g^{n}\right)\right\} \\
& C^{r}=E_{i}^{r}\left\{\left(g_{i}^{r}-g_{i}^{n}\right)\right\},
\end{aligned}
$$

where the national-growth component, $N^{r}$, is given by regional employment in the $i$ th industry, $E_{i}^{r}$, times the overall rate of employment change in the nation (the reference economy), $g^{n}$. Thus the national-growth component gives the employment growth that would have occurred if the region had experienced the same growth as the reference economy. The industrial-mix component, $I^{r}$, is given by regional employment in the $i$ th industry, $E_{i}^{r}$, times the national rate of employment change in the ith industry, $g_{i}^{n}$, less the overall rate of employment change in the nation, $g^{n}$. Thus the industrial mix gives the growth that would have occurred in the region if each regional industry had displayed the same rate of growth as that industry in the reference economy and is often viewed as a measure of the strength of the industrial base of the region. The competitive component, $C^{r}$, is given by regional employment in the ith industry, $E_{i}^{r}$, times the regional rate of employment change in the ith industry, $g_{i}^{r}$, less the national rate of employment change in the ith industry, $g_{i}^{n}$. This component is often interpreted as the locational advantage (disadvantage) of the specific industry in the region.

In this paper, the shift-share analysis is extended beyond its conventional application of assessing regional industrial performance by accounting for the impact of regional economic growth or decline on particular age-sex cohorts. To accommodate the effect of regional economic performance on particular age-sex cohorts, the conventional shiftshare model is modified according to the following specification:

$$
\begin{aligned}
& N_{a}^{r}=E_{i a}^{r} g^{n} \\
& I_{a}^{r}=E_{i a}^{r}\left\{\left(g_{i}^{n}-g^{n}\right)\right\} \\
& C_{a}^{r}=E_{i a}^{r}\left\{\left(g_{i a}^{r}-g_{i}^{n}\right)\right\},
\end{aligned}
$$

where the national-growth component, $N_{a}^{r}$, is given by regional employment in the $i$ th industry for a particular age-sex cohort, $E_{i a}^{r}$, times the overall rate of employment change in the nation (reference economy), $g^{n}$; the industrial-mix component, $I_{a}^{r}$, is given by regional employment in the $i$ th industry for the particular age-sex cohort, $E_{i a}^{r}$, times 
the national rate of employment change in the ith industry, $g_{i}^{n}$, less the overall rate of employment change in the nation, $g^{n}$; and the competitive component, $C_{a}^{r}$, is given by regional employment in the $i$ th industry for the particular age-sex cohort, $E_{i a}^{r}$, times the regional rate of employment change in the ith industry for the particular age-sex cohort, $g_{i a}^{r}$, less the national rate of employment change in the ith industry, $g_{i}^{n}$.

Thus our disaggregated version of the model treats each age-sex specific cohort in each region as a separate subregion of its own, in reference to aggregate economic performance. ${ }^{1}$ Accordingly, the national-growth component gives the employment change that would have occurred if the employment for the particular age-sex cohort in the region had matched the overall national average for all age-sex cohorts, i.e., the reference economy. The industrial-mix component gives the employment growth that would have occurred for the particular age-sex cohort for a given industry in the region if the industry employment growth had been at the relevant national average for that industry. The industrial mix is interpreted as a measure of the structural strength (weakness) of the industrial base of the region. The competitive-share component is interpreted as the locational advantages (disadvantages) of each age-sex employment cohort for each particular industry, measured by the actual employment growth for each age-sex cohort in the relevant regional industry minus the relative national average growth for that particular industry.

The raw data utilized in the computations are drawn from Statistics Canada's Labour Force Survey and have been retrieved from CANSIM II, Table $2820007 .^{2}$ Based on annual averages by the two-digit standard industrial code, multi-dimensional tables for the period extending from 1976 to 1995 have been constructed according to age, genderspecific, and total employment for the Atlantic Region, Quebec, Ontario, the Prairie Region, and British Columbia. In this study we classify younger workers to be aged 15 to 24 years, adult workers aged 25 to 54 years, and older workers aged 55 plus.

While the traditional shift-share model is able to provide insights to the direction and magnitude of employment changes, it is silent with respect to the significance of such impacts. Patterson (1991) suggested the use of a full-analogue regression model of the shift-share method as one way to overcome this problem. The form of the model suggested by Patterson is as follows:

$$
Y=(E U+E V+E W) \beta+\varepsilon,
$$

\footnotetext{
${ }^{1}$ Alternatively, one could treat the national performance of age-sex specific cohorts as the reference economy and conduct the shift-share analysis independently for each age-sex component. Our approach allows us to compare the performance of age-sex specific cohorts to the overall level of economic performance, while the alternative approach would give a more direct measure of the relative status of an age-sex cohort compared to the same cohort nationally.

${ }^{2}$ CANSIM II is Statistics Canada's computerized database.
} 
where

$Y$ is a vector of the growth or decline in employment for every industry by region; ${ }^{3}$

$E$ is a diagonal matrix representing the employment weight for each industry-byregion combination in the base year;

$U$ is a matrix representing the national dummy variable;

$V$ is a matrix consisting of industry fixed-effect variables;

$W$ is a matrix of regional fixed-effect variables (in our case, including dummies for each age-sex cohort by region);

$\beta$ is a vector of coefficients and $\varepsilon$ is a vector of residuals.

Since the $X^{\prime} X$ matrix is singular as specified, one industry dummy and one regional dummy could be dropped. The suppressed coefficients could then be recovered from the adding-up constraints and the resulting coefficients normalized to reflect the requirements of the traditional shift-share model. However, following Patterson (1991), the required adding-up constraints may be applied directly to the maximum likelihood estimation.

$$
v_{N 1} b_{i 1}+v_{N 2} b_{i 2}+\ldots+v_{N p} b_{i p}=0
$$

and

$$
w_{N 1} b_{r 1}+w_{N 2} b_{r 2}+\ldots+w_{N q} b_{r q}=0
$$

These restrictions imply that the sum of the weighted industry effects and the weighted regional effects must both add up to the national employment changes.

As noted by Blien and Wolf (2002), the shift-share regression model has several advantages over the use of panel data, which treats the region as the base of analysis. These include the ability to separate the effects of industry and region and, in our case, the effects of differences in age-sex specific cohorts. Additionally, since the shift-share regression model is based on employment of age-sex specific cohorts in each industry in each region, the estimation precision is improved because of the increased number of observations.

Brox and Carvalho (2007) suggested a way of adjusting the demographically enhanced shift-share model for changes in labour force. The regression analogue of this version of the model may be estimated by redefining the dependent variable in equation

\footnotetext{
${ }^{3}$ In our case the region is defined as a specific age-sex cohort in the region. Thus we have six agesex cohorts for each of the five regions considered, giving us a total of 30 sub-regions.
} 
(7) as $Y-L$, a vector of the growth or decline in employment minus the change in labour force, for every industry by region. Thus the model now becomes:

$$
Y-L=(E U+E V+E W) \beta+\varepsilon,
$$

where

$Y$ is a vector of the growth or decline in employment for every industry by region;

$L$ is a vector of the growth or decline in the labour force for every industry by region;

$E$ is a diagonal matrix representing the employment weight for each industry-byregion combination in the base year;

$U$ is a matrix representing the national dummy variable;

$V$ is a matrix consisting of industry fixed-effect variables;

$W$ is a matrix of regional fixed-effect variables (in our case, including dummies for each age-sex cohort by region);

$\beta$ is a vector of coefficients and $\varepsilon$ is a vector of residuals.

Since the $X^{\prime} X$ matrix is still singular as specified, one industry dummy and one regional dummy could be dropped. The suppressed coefficients could then be recovered from the adding-up constraints and the resulting coefficients normalized to reflect the requirements of the traditional shift-share model. However, following the procedure outlined above, the required adding-up constraints: may be applied directly to the maximum likelihood estimation.

$$
v_{N 1} b_{i 1}+v_{N 2} b_{i 2}+\ldots+v_{N p} b_{i p}=0
$$

and

$$
w_{N 1} b_{r 1}+w_{N 2} b_{r 2}+\ldots+w_{N q} b_{r q}=0
$$

These restrictions imply that the sum of the weighted industry effects and the weighted regional effects must both add up to the net ${ }^{4}$ national employment changes.

\footnotetext{
${ }^{4}$ Net in this case implies after adjustment for changes in the labour force in the corresponding industry, age-sex cohort, and region.
} 


\section{ANALYSIS}

The results of estimating this model using the shift-share data discussed above are reported in Table 1. The overall fit of the regression, as measured by the adjusted $\mathrm{R}^{2}$, is quite good. The national growth rate of total employment estimated by the model is 25.5 percent per decade. The second period, 1986-1995, reveals a growth rate 8.9 percent slower than the full period. Both of these effects are found to be statistically significant. Brox and Carvalho (2002), using the traditional version of the demographically enhanced shift-share model, estimated the growth rate of employment over the 1976 to 1985 period to be 20 percent and 15 percent for the 1986 to 1995 period, reflecting the impact of the severe and prolonged recession in the early $1990 \mathrm{~s}^{5}$

\section{TABLE 1}

Regression Results for the Shift-Share Model

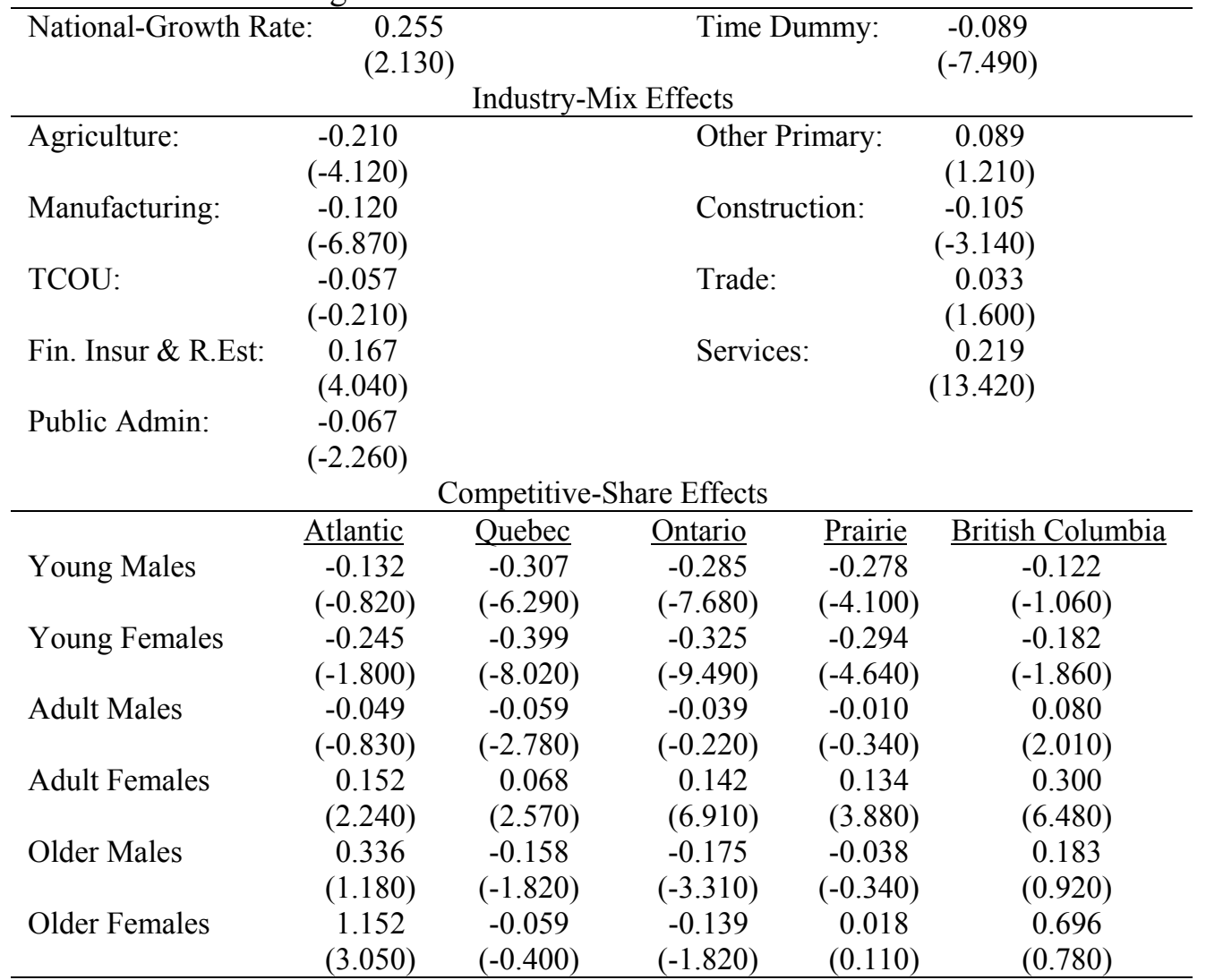

Figures in parentheses are the t-ratios

$\mathrm{R}$-square between observed and predicted $=0.8772$

${ }^{5}$ The results from Brox and Carvalho (2002) differ as they refer to the provinces of Ontario and Quebec, while this study also includes data from the Atlantic and Prairie regions as well as the province of British Columbia. 
When we turn to the industrial-mix components, ${ }^{6}$ finance and services are found to have a statistically significant positive effect. On the other hand, agriculture, manufacturing, construction, and public administration are significant employment losers. The results from the remaining three sectors are mixed, with other primary and trade being relative gainers but utilities being a net loser, with none of these effects being estimated to be significantly different from zero.

With respect to the competitive share, ${ }^{7}$ we find a considerable amount of variation across the country. For Atlantic Canada, we find negative growth for younger workers and adult males and positive growth for older workers and adult females. Further, we find that the effects for females are significantly different from zero, while those for males are not.

For Quebec and Ontario, we find negative employment growth for all cohorts except adult females, which display effects significantly greater than zero. For the Prairie region, all cohorts except for adult and older females display negative employment growth, with adult females exhibiting effects significantly greater than zero. Finally, in British Columbia young workers suffered negative while adult and older workers experienced positive employment gains over the period. However, only the effects for adult workers are statistically significantly different from zero.

Across the country, we find that younger workers have suffered negative employment changes over the period, with all effects being statistically significant except for young males in the Atlantic region and British Columbia. ${ }^{8}$ These findings support the proposition that a shortage of suitable job prospects has motivated young workers to extend their time in school (Boothby and Drewes 2006).

Outside the Atlantic region, older workers have been found to have no significant change except for Ontario and male workers in Quebec, where significant declines are identified. These results are indicative of job losses and early retirements attributed to the restructuring, downsizing, and relocation of industries observed in sectors such as manufacturing that are more heavily concentrated in the central Canadian regions of Ontario and Quebec.

For adult female workers, the estimates indicate significantly positive changes in every region of the country. Adult male workers have a significantly positive effect in British Columbia and a significantly negative effect in Quebec. Everywhere else, the

\footnotetext{
${ }^{6}$ A positive industrial mix implies that the industry in question is growing faster than the national average.

${ }^{7}$ A positive competitive-share effect in normal shift-share analysis implies that the employment growth in the industry in the given region exceeds that in the industry nationally. In this study, this is modified to include the relative position of each age-sex cohort employment in the regional industry, compared with the national position of the same industry.

${ }^{8}$ The decline for young females in the Atlantic Region and British Columbia is statistically significant at the 10 percent level.
} 
model indicates no significant changes in male employment patterns. The favourable results obtained for female workers attests to their possession of qualifications required to obtain and successfully maintain employment in growth sectors such as services and finance, insurance, and real estate.

Finally, the weak performance registered by the younger, more educated, and more skilled cohorts accounts for the segments of the labour force contributing to the noted out-migration from the Atlantic region (Finnie and Meng 2001). In contrast, the positive performance exhibited by the adult and older cohorts in the region attests to the province of British Columbia remaining a desired destination in which to retire eventually.

Table 2 shows the results for the version of the model adjusted for changes in the labour force for each region, age-sex cohort, and industry. For the industry-mix components the adjustment for changes in the labour force has relatively little effect. The signs and significance show the same patterns: weakness for agriculture, manufacturing, construction, and public administration and strength for trade and finance, real estate, and services. Here both strength and weakness is defined as employment growth minus growth in the labour force being positive or negative.

With respect to the competitive or regional effects, some significant differences are found. Most of the significant gains made by the female cohorts disappear after adjustment for changes in the labour force. Indeed the significant effects that are found in Table 2 (i.e., adults in Quebec and Ontario and the older group in Ontario and British Columbia) indicate weakness for the female cohorts. Adult males are generally found to display employment growth exceeding the growth in the labour force. Finally, younger and older males have a more mixed outlook, with many of the effects not being statistically significant. However, growth after adjustment for labour-force changes is seen to be more positive than that implied by the original version of the model.

\section{SUMMARY AND POLICY RECOMMENDATIONS}

The results of this study clearly indicate that adult workers have fared better than either young or older workers in terms of relative employment growth over the time period considered. These results would tend to suggest that the recent trend towards early retirement for older workers ${ }^{9}$ has not significantly reduced the employment problem facing younger cohorts. When the sex cohorts are considered, it appears that in most age groups, females have fared better than corresponding male groups.

While the results indicated above are found to be significant in terms of actual changes, this study has little to say concerning desired changes. For example, relative declines in young or older workers may be the result of changes in participation rates rather than changes in employment opportunities. Likewise, while the regression

\footnotetext{
${ }^{9}$ For discussion of the trend to early retirement in Canada, see Kieran (2001), Baker and Benjamin (1999), and Gunderson and Luchak (2001).
} 
analogue model has an advantage over the traditional shift-share model in that it is able to separate significant effects from those not significantly different from zero, it shows what has happened but not why. That is, the model helps to identify what has occurred, but it does not shed light on the reasons for the various changes.

The industry-mix effects are clear and not overly surprising. Such results, especially when extended to more disaggregate data, provide the basis for labour training policies. Further, when considering the competitive-share effects, we note some major differences across the various regions. This implies that labour-market policies would be best addressed at a relatively localized level.

\section{TABLE 2}

Regression Results for the Labour-Force Adjusted Shift-Share Model

\begin{tabular}{|c|c|c|c|c|c|}
\hline \multicolumn{2}{|c|}{ National-Growth Rate: } & $\begin{array}{l}-0.127 \\
(-5.150)\end{array}$ & \multicolumn{2}{|c|}{ Time Dummy: } & $\begin{array}{c}0.066 \\
(6.330)\end{array}$ \\
\hline \multicolumn{6}{|c|}{ Industry-Mix Effects } \\
\hline Agriculture: & \multicolumn{2}{|l|}{$\begin{array}{c}-0.246 \\
(-5.830)\end{array}$} & \multicolumn{2}{|c|}{ Other Primary: } & $\begin{array}{c}-0.028 \\
(-0.460)\end{array}$ \\
\hline Manufacturing: & \multicolumn{2}{|l|}{$\begin{array}{c}-0.088 \\
(-5.910)\end{array}$} & Construction: & \multicolumn{2}{|c|}{$\begin{array}{c}-0.086 \\
(-3.030)\end{array}$} \\
\hline TCOU: & \multicolumn{2}{|l|}{$\begin{array}{c}0.013 \\
(0.530)\end{array}$} & Trade: & \multicolumn{2}{|c|}{$\begin{array}{c}0.066 \\
(3.960)\end{array}$} \\
\hline Fin. Insur \& R.Est & $\begin{array}{c}0.163 \\
(4.660)\end{array}$ & & Services: & \multicolumn{2}{|c|}{$\begin{array}{c}0.260 \\
(18.530)\end{array}$} \\
\hline \multirow[t]{2}{*}{ Public Admin: } & $\begin{array}{c}-0.054 \\
(-1.770)\end{array}$ & & & & \\
\hline & \multicolumn{4}{|c|}{ Competitive-Share Effects } & \\
\hline Young Males & $\begin{array}{l}\text { Atlantic } \\
0.073 \\
(0.530)\end{array}$ & $\begin{array}{c}\text { Quebec } \\
0.135 \\
(3.040)\end{array}$ & $\begin{array}{c}\frac{\text { Ontario }}{0.052} \\
(1.560)\end{array}$ & $\begin{array}{c}\text { Prairie } \\
0.019 \\
(0.330)\end{array}$ & $\begin{array}{c}\text { British Columbia } \\
0.069 \\
(0.710)\end{array}$ \\
\hline Young Females & $\begin{array}{c}-0.063 \\
(-0.560)\end{array}$ & $\begin{array}{l}-0.016 \\
(-0.370)\end{array}$ & $\begin{array}{c}-0.013 \\
(-0.380)\end{array}$ & $\begin{array}{l}-0.029 \\
(-0.540)\end{array}$ & $\begin{array}{c}-0.028 \\
(-0.340)\end{array}$ \\
\hline Adult Males & $\begin{array}{c}0.057 \\
(1.100)\end{array}$ & $\begin{array}{c}0.089 \\
(3.470)\end{array}$ & $\begin{array}{c}0.080 \\
(3.340)\end{array}$ & $\begin{array}{c}0.048 \\
(1.500)\end{array}$ & $\begin{array}{c}0.041 \\
(1.990)\end{array}$ \\
\hline Adult Females & $\begin{array}{c}-0.043 \\
(-0.770)\end{array}$ & $\begin{array}{c}-0.060 \\
(-2.190)\end{array}$ & $\begin{array}{c}0.017 \\
(0.690)\end{array}$ & $\begin{array}{c}-0.016 \\
(-0.510)\end{array}$ & $\begin{array}{c}-0.013 \\
(-0.320)\end{array}$ \\
\hline Older Males & $\begin{array}{c}0.019 \\
(0.080)\end{array}$ & $\begin{array}{c}0.084 \\
(1.140)\end{array}$ & $\begin{array}{c}0.058 \\
(1.220)\end{array}$ & $\begin{array}{c}0.161 \\
(1.660)\end{array}$ & $\begin{array}{c}-0.013 \\
(-0.330)\end{array}$ \\
\hline Older Females & $\begin{array}{c}-0.191 \\
(-0.530)\end{array}$ & $\begin{array}{c}-0.170 \\
(-1.350)\end{array}$ & $\begin{array}{c}-0.127 \\
(-1.840)\end{array}$ & $\begin{array}{c}-0.139 \\
(-0.950)\end{array}$ & $\begin{array}{c}-0.011 \\
(-1.780)\end{array}$ \\
\hline
\end{tabular}

Figures in parentheses are the t-ratios

R-square between observed and predicted $=0.6923$ 
Considering the version of the model adjusting for changes in the labour force, we find some significant results. The industry-mix components tell largely the same as for the non-labour force adjusted version. However, the competitive-share effects have changed dramatically. The significant positive effects found for the female cohorts have disappeared, with the effects that remain statistically significant now being found to be negative. This implies that the strong gains in female employment found in the first model are the result of strong growth in the female labour force caused by raising female participation rates in the period. Also, the significant negative employment growth found for younger and older males in the first version of the model has been replaced with positive growth, again implying that the changes are the result of labour-force pressures.

\section{REFERENCES}

Anderson, J.B. and D. Dimon, 1999. "Formal Sector Job Growth and Women's Labor Sector Participation: The Case of Mexico," Quarterly Review of Economics and Finance 39(2), 169-91.

Andrikopoulos A., J.A. Brox, and E. Carvalho, 1987. "A Further Test of the Competitive Effect in Shift-Share Analysis," The Review of Regional Studies 17, 23-30.

, 1990. "Shift-Share Analysis and the Potential for Predicting Regional Growth Patterns: Some Evidence for the Region of Quebec, Canada," Growth and Change 21, 1-10.

Arcelus, F.J., 1984. "An Extension of Shift-Sharing," Growth and Change, 15(1), 72-82.

Ashby, L.D., 1968. "The Shift and Share Analysis: A Reply," Southern Economic Journal 34, 423-25.

Baker, M. and D. Benjamin, 1999. "Early Retirement Provisions and the Labor Force Behavior of Older Men: Evidence from Canada," Journal of Labor Economics 17(4), 724-56.

Bishop K.C. and C.E. Simpson, 1972. "Components of Change Analysis: Problems of Alternative Approaches to Industrial Structure," Regional Studies 6, 59-68.

Blien, U. and K. Wolf, 2002. "Regional Development of Employment in Eastern Germany: An Analysis with an Econometric Analogue to Shift-Share Techniques," Papers in Regional Science 81, 391-414.

Boothby, D. and T. Drewes, 2006. "Postsecondary Education in Canada: Returns to University, College and Trades Education," Canadian Public Policy 32(1), 1-21.

Bottoms, G., 1981. Youth Unemployment: Solving the Problem, The American Vocational Association: New York.

Brown, H.J., 1969. "Shift and Share Projections and Regional Economic Growth: An Empirical Test," Journal of Regional Science 9, 1-18.

Brox J.A. and E. Carvalho, 2002. "Sectoral Labour Market Adjustment in the Provinces of Ontario and Quebec," Canadian Journal of Regional Science 25(3), 405-22.

, 2007, “A Demographically Augmented Shift-Share Employment Analysis: An Application to Canadian Employment Patterns," Journal of Regional Analysis and Policy 37(1).

Chalmers, J.A. and T.L. Beckhelm, 1976. "Shift and Share and the Theory of Industrial Location," Regional Studies 10, 15-23. 
Chebbi, H.E. and J.M. Gil, 2002. "Position Competitive des Exportations Tunisiennes de Dattes sur le Marché Européen: Une Analyse Shift-Share," Mediterranean Journal of Economics, Agriculture and Environment 1(3), 40-7.

Coughlin, C.C. and P.S. Pollard, 2001. "Comparing Manufacturing Export Growth Across States: What Accounts for the Differences?" Federal Reserve Bank of St. Louis Review 83(1), 25-40.

Danson, M.W., W.F. Lever, and J.F. Malcolm, 1980. "The Inner City Employment Problem in Great Britain, 1952-1976: A Shift-Share Approach," Urban Studies 17, 193-210.

Dussel-Peters, E., 1995. "Recent Developments in Mexican Employment and the Impact of NAFTA," International Contributions to Labour Studies 5, 45-69.

Ehrenberg, R.G., 1994. Labor Markets and Integrating National Economies, Brookings Institution: Washington, D.C.

Esteban, J., 2000. "Regional Convergence in Europe and the Industry Mix: A Shift-Share Analysis," Regional Science and Urban Economics 30, 353-64.

Esteban-Marquillas, J., 1972. "A Reinterpretation of Shift-Share Analysis," Regional and Urban Economics 23, 249-61.

Finnie, R. and R. Meng, 2001. "Cognitive Skills and the Youth Labour Market," Applied Economics Letters 8(10), 675-79.

Fothergill, S. and G. Gudgin, 1979. "In Defense of Shift-Share," Urban Studies 17, 193210.

Gabriel, C. and L. Macdonald, 1996. "NAFTA and Economic Restructuring: Some Gender and Race Implications," in I. Bakker (ed.), Rethinking Restructuring: Gender and Change in Canada, University of Toronto Press: Toronto.

Gunderson, M. and A. Luchak, 2001. "Employee Preferences for Pension Plan Features," Journal of Labor Research 22(4), 795-808.

Hostland, D., 1985. "What Factors Determine Structural Unemployment in Canada," Human Resources Development Canada.

Houston, D., 1967. "Shift-Share Analysis: A Critique," Southern Economic Journal 33, 577-81.

Ireland, T.C. and R.L. Moomaw, 1981. "The Competitive Effect in Shift-Share Analysis: A Will of the Wisp?" The Review of Regional Studies 11, 72-82.

Keil, S.R., 1992. "On the Value of Homotheticity in the Shift-Share Framework," Growth and Change 23(4), 469-93.

Kieran, P., 2001. "Early Retirement Trends," Perspectives on Labour and Income 13(4), 7-13.

Loveridge, S. and A.C. Selting, 1998. "A Review and Comparison of Shift-Share Identities," International Regional Science Review 21(1), 37-58.

Markusen, A.R., H. Noponen, and K. Driessen, 1991. "International Trade, Productivity, and U.S. Regional Job Growth: A Shift-Share Interpretation," International Regional Science Review 14(1), 15-39.

McDonough, C.C. and B.S. Sihag, 1991. "The Incorporation of Multiple Bases into ShiftShare Analysis," Growth and Change 22(1), 1-9. 
Melachroinos, K.A., 2002. "European Integration and the Spatial Dynamics of Manufacturing-Employment Change," Environment and Planning A 34(11), 201736.

O'Leary, E., 2003. "Aggregate and Sectoral Convergence Among Irish Regions: The Role of Structural Change, 1960-96," International Regional Science Review 26(4), 483-501.

Patterson, M.G., 1991. "A Note on the Formulation of a Full-Analogue Regression Model of the Shift-Share Method," Journal of Regional Science 31(2), 211-16.

Richardson, H.W., 1978. Urban and Regional Economics, Penguin: New York.

Rigby, D.L. and W.P. Anderson, 1993. "Employment Change, Growth and Productivity in Canadian Manufacturing: An Extension and Application of Shift-Share Analysis," Canadian Journal of Regional Science 16(1), 69-88.

Timmer, M.P. and A. Szirmai, 2000. "Productivity Growth in Asian Manufacturing: The Structural Bonus Hypothesis Examined," Structural Change and Economic Dynamics 11, 371-92.

Statistics Canada, Labour Force Survey, Industry Employment by Age Group, obtained from CANSIM II, Table 2820007, Ottawa.

Zhao, S.X.B., C.S.P. Tong, and J.M. Qiao, 2004. "Spatial Change in China's Industrial Structure," Geography 89, 127-39. 